\title{
Hepatitis C Infection is Associated With Increased Coronary Artery Atherosclerosis Defined by Modified Reardon Severity Score System
}

\author{
Omer Alyan, MD*; Fehmi Kacmaz, MD; Ozcan Ozdemir, MD**; Bulent Deveci, MD \\ Ramazan Astan, MD ${ }^{\dagger ;}$; Aksuyek Savas Celebi, MD*; Erdogan Ilkay, MD
}

\begin{abstract}
Background The link between arteriosclerotic disease in the carotid or coronary artery and chronic hepatitis C virus $(\mathrm{HCV})$ infection has been shown in some studies although other studies have produced contrary results. However, the effect of chronic HCV infection on the extension or severity of coronary artery disease (CAD) has not been determined so the aim of the present study was to determine the effect of $\mathrm{HCV}$ infection on the severity of CAD.

Methods and Results The study group comprised $139 \mathrm{HCV}$ seropositive and $225 \mathrm{HCV}$ seronegative patients with angiographically documented CAD. A modified scoring system of Reardon et al was used. There were no significant differences between groups in terms of sex, age, hypertension, diabetes mellitus, smoking or family history. Levels of C-reactive protein and fibrinogen were significantly higher in the HCV seropositive group $(\mathrm{p}<0.001)$ and the Reardon severity score was higher $(8.75 \pm 1.69$ vs $6.01 \pm 1.80, p<0.001)$. After adjustment, HCV seropositivity still represented an independent predictor for severity of coronary atherosclerosis demonstrated by higher Reardon severity score with an odds ratio of 2.018 (95\% confidence interval 1.575-2.579, $\mathrm{p}<0.001$ ).

Conclusion HCV infection is an independent predictor for increased coronary atherosclerosis, as demonstrated by higher Reardon severity score. (Circ J 2008; 72: 1960-1965)
\end{abstract}

Key Words: Atherosclerosis; Hepatitis C infection; Inflammation; Scoring

$\mathbf{S}$ everal previous studies have suggested a link between arteriosclerotic disease and persistent infection or seropositivity of certain microorganisms, such as Chlamydia pnuemoniae, cytomegalovirus, Helicobacter pylori, and herpes simplex virus ${ }^{1-5}$ although the underlying mechanism has yet to be fully elucidated. The possible role of certain infectious agents in atherogenesis has been suggested by recent observations that viable microorganisms or remnants of them are present in atherosclerotic plaque ${ }^{6}$ and that a positive antibody status against some infectious organisms is associated with atherosclerotic diseases? On the other hand, several investigators have reported experimental and epidemiological evidence that suggests activation of an inflammatory process, rather than the specific infectious agent, is responsible for the development and promotion of athero-

(Received May 8, 2008; revised manuscript received July 17, 2008; accepted July 23, 2008; released online October 29, 2008)

Department of Cardiology, Bingol State Hospital, Bingol, *Department of Cardiology, Dicle University, Diyarbakir, **Department of Cardiology, Akay Hospital, Ankara, Department of Cardiology, Veni Vidi Hospital, Diyarbakir, tDepartment of Cardiology, Turkiye Yuksek Ihtisas Hospital, Department of Cardiology, Numune Hospital and \#Department of Cardiology, Ozel Mesa Hospital, Ankara, Turkey

This study has been accepted as a poster presentation at The World Congress of Cardiology 2008, Buenos Aires, Argentina and an abstract has been published in Circulation (Journal of the American Heart Association).

Mailing address: Fehmi Kacmaz, MD, Department of Cardiology, Bingol Devlet Hastanesi, Kardiyoloji Klinigi 12100, Bingol, Turkey. E-mail: kacmazfehmi@superonline.com or drfehmikacmaz@yahoo. com

All rights are reserved to the Japanese Circulation Society. For permissions, please e-mail: cj@j-circ.or.jp sclerotic diseases. ${ }^{8} 9$ Infective agents may have a proinflammatory effect and thus a crucial role in atherothrombosis $!^{10}$

Many additional results have shown an association between infectious agents and the atherosclerotic process, although other studies have produced contrary results $!^{0}$ Thus, the role of infection in the pathogenesis of this disease remains controversial. One of these infectious agents is hepatitis $\mathrm{C}$ virus (HCV), which infects approximately 170 million individuals worldwide. This infection remains a severe life-threatening medical and public health problem. In the current literature, there are very few data on the relationship between $\mathrm{HCV}$ infection and atherosclerosis. However, very recent results indicate that seropositivity for $\mathrm{HCV}$ shows a positive association with carotid artery plaque and carotid intima-media thickening, independent of other risk factors for atherosclerosis! 1

In the present study, we evaluated whether seropositivity for $\mathrm{HCV}$ is associated with the severity or exacerbation of atherosclerosis in coronary artery disease $(\mathrm{CAD})$ proven subjects.

\section{Methods}

\section{Patients and Study Design}

In the present study, 28,708 consecutive patients underwent coronary angiography between May 2003 and September 2007 and the $139(0.4 \%)$ who had angiographically documented CAD ( $>50 \%$ stenosis) with HCV seropositivity were enrolled. The control group comprised 225 patients with $\mathrm{HCV}$ seronegativity and angiographically documented CAD. All the enrolled patients had been admitted to Turkiye Yuksek Ihtisas Education and Research 
Table 1 Baseline Characteristics and Laboratory Results

\begin{tabular}{lccc}
\hline \hline & $\begin{array}{c}\text { HCV seropositive } \\
\text { group }(n=139)\end{array}$ & $\begin{array}{c}\text { HCV seronegative } \\
\text { group }(n=225)\end{array}$ & p value \\
\hline Age, years & $61.2 \pm 9.0$ & $60.6 \pm 10.7$ & 0.383 \\
Male gender, $n(\%)$ & $106(76.3)$ & $168(74.7)$ & 0.803 \\
Systolic blood pressure, mmHg & $128.4 \pm 13.5$ & $127.6 \pm 11.8$ & 0.873 \\
Diastolic blood pressure, $m$ mHg & $76.8 \pm 12.9$ & $75.7 \pm 12.6$ & 0.769 \\
Systemic hypertension, $n(\%)$ & $69(49.6)$ & $115(51.1)$ & 0.829 \\
Diabetes mellitus, $n(\%)$ & $38(27.3)$ & $42(18.7)$ & 0.068 \\
Active smoker, $n(\%)$ & $47(33.8)$ & $71(31.6)$ & 0.730 \\
Family history, $n(\%)$ & $33(23.7)$ & $42(18.7)$ & 0.286 \\
LDL-cholesterol, $m g / d l$ & $109.1 \pm 33.5$ & $118.6 \pm 41.1$ & $<0.001$ \\
HDL-cholesterol, $m g / d l$ & $37.9 \pm 22.4$ & $43.1 \pm 28.2$ & 0.062 \\
Hemoglobin Alc, $\%$ & $6.41 \pm 0.63$ & $6.38 \pm 0.58$ & 0.358 \\
AST, U/L & $27.3 \pm 11.8$ & $25.6 \pm 9.2$ & 0.368 \\
ALT, U/ml & $30.1 \pm 12.6$ & $27.9 \pm 11.7$ & 0.345 \\
CRP, $m g / L$ & $2.073 \pm 1.358$ & $1.190 \pm 1.005$ & $<0.001$ \\
Fibrinogen, $m g / d l$ & $5.323 \pm 1.567$ & $4.104 \pm 1.648$ & $<0.001$ \\
\hline
\end{tabular}

Values are mean $\pm S D$ or number and percentage of patients.

$H C V$, hepatitis $C$ virus; $L D L$, low-density lipoprotein; $H D L$, high-density lipoprotein; AST, aspartate transaminase; ALT, alanine transaminase; $C R P, C$-reactive protein.

Hospital with complaints such as angina, dyspnea, palpitation or syncope. The total group of 364 patients (mean age $60.6 \pm 10.1$ years and $75 \%$ males) was divided in 2 groups according to anti-HCV serology. Patients in the HCV seropositive group had HCV seropositivity without clinical liver disease. Patients with seropositivity for $\mathrm{HBsAg}$, severe liver damage and cirrhosis, acute or chronic inflammatory disease, immunological disease, and a history or the presence of neoplastic disease were excluded. In addition, patients without stenosis $>50 \%$ of at least 1 main coronary vessel or with stenosis of a minor vessel or main coronary artery branch were excluded.

\section{Serological Assays}

Venous blood samples were collected from the patients under standardized conditions after an overnight fast and were centrifuged within $15 \mathrm{~min}$ of collection $(3,000 \mathrm{~g}$ for $10 \mathrm{~min})$. Serum samples were immediately analyzed for antibodies against $\mathrm{HCV}$ using a third-generation enzyme immunoassay (EIA) laboratory technique that detects antibodies directed against various HCV epitopes. Recombinant antigens were used to capture circulating anti-HCV antibodies onto the wells of microtiter plates, microbeads, or specific holders adapted to closed automated devices. The presence of anti-HCV antibodies was revealed by anti-antibodies labeled with an enzyme that catalyzes the transformation of a substrate into a colored compound. The specificity of third-generation EIAs for anti-HCV is reported as greater than $99 \% !^{12}$ The sensitivity of third-generation EIAs is more difficult to determine, given the lack of a gold standard method, but it is excellent in HCV-infected immunocompetent patients. EIAs can be fully automated and are well adapted to large-volume testing. Immunoblot tests are nowadays clinically obsolete given the good performance of third-generation anti-HCV EIAs! ${ }^{13}$

\section{Measurement of Circulating C-Reactive Protein (CRP)}

Blood samples were collected into tubes containing citric acid and stored at $-80^{\circ} \mathrm{C}$ after centrifugation. The stored serum for each patient was thawed for CRP measurement by an automatic immunonephelometer.
Interpretation of Coronary Angiograms for the Severity of Atherosclerosis

Coronary arteriography (Siemens axion artic PC, Germany) was performed in all patients by the Judkins technique and all angiograms were reviewed by 2 cardiologists who had no knowledge of the patient's clinical history or laboratory results. The average score of the 2 reviewers was obtained to calculate the exact score for each patient. Scoring for severity of CAD was performed with a scoring system described previously 14 that was modified by Reardon et al ${ }^{15}$ The coronary circulation was divided into 8 segments for analysis. The 8 proximal segments including the left anterior descending artery (LAD) up to the junction of the middle and distal third of the vessel, the proximal third of the major septal branch of the LAD, the proximal third of the major diagonal branch of the LAD, the circumflex coronary artery (CFX), the proximal third of the major obtuse marginal branch of the CFX, the right coronary artery (RCA) up to and the origin of the posterior descending coronary artery (PDA) and the proximal third of the PDA were determined. Disease in the distal segment of each coronary artery was not considered because of the difficulty in quantifying the severity of lesions in those areas. In cases in which the CFX was the dominant coronary artery (the PDA was supplied by CFX), lesions in the CFX up to the origin of the PDA were included, as were lesions of the RCA up to the origin of the middle and distal thirds of the vessel.

The percentage narrowing of each lesion in the proximal coronary artery circulation was assessed according to the maximal narrowing of the diameter of the artery in all projections. The extend and severity of the proximal coronary disease was assessed by assigning points to each lesion as follows: $<50 \%$ stenosis of the luminal diameter, 1 point; 50 $74 \%, 2$ points; $75-99 \%, 3$ points; $100 \%$ or total obstruction, 4 points. The points for each lesion in the proximal coronary circulation were summed to give the score for severity.

\section{Statistical Analysis}

Data were analyzed with SPSS software version 11.5 for Windows (SPSS Inc, Chicago, IL, USA). Continuous data are presented as means \pm SD. Differences in continuous variables between groups were determined by Student's t-test (normal) or Mann-Whitney U-test (non-normal). Cate- 
Table 2 Comparison of Medications Affecting Progression of Coronary Atherosclerosis

\begin{tabular}{lccc}
\hline \hline & $\begin{array}{c}\text { HCV seropositive } \\
\text { group }(n=139)\end{array}$ & $\begin{array}{c}\text { HCV seronegative } \\
\text { group }(n=225)\end{array}$ \\
\hline Aspirin & $78.7 \pm 9.2$ & $76.3 \pm 7.9$ & 0.671 \\
$\beta$-blocker & $67.0 \pm 11.7$ & $66.9 \pm 10.3$ & 0.835 \\
ACEI/ARB & $61.9 \pm 10.1$ & $62.1 \pm 11.5$ & 0.879 \\
Calcium-channel blocker & $45.2 \pm 15.5$ & $43.9 \pm 13.0$ & 0.792 \\
Statins & $73.9 \pm 9.1$ & $72.7 \pm 8.7$ & 0.749 \\
\hline
\end{tabular}

ACEI, angiotensin-converting enzyme inhibitor, ARB, angiotensin-receptor blocker.

Table 3 Comparison of Angiographic Parameters

\begin{tabular}{lccc}
\hline \hline & $\begin{array}{c}\text { HCV seropositive } \\
\text { group }(n=139)\end{array}$ & $\begin{array}{c}\text { HCV seronegative } \\
\text { group }(n=225)\end{array}$ & $\begin{array}{c}p \text { value } \\
\text { Reardon severity score }\end{array}$ \\
Multivessel disease $(\geq 2$ vessels $), n(\%)$ & $8.75 \pm 1.69$ & $6.01 \pm 1.80$ & $<0.001$ \\
Collateral coronary vessels, $n(\%)$ & $126(91.6)$ & $166(74.1)$ & $<0.001$ \\
0.001 & $22(9.8)$ & \\
\hline
\end{tabular}

Abbreviation see in Table 1.

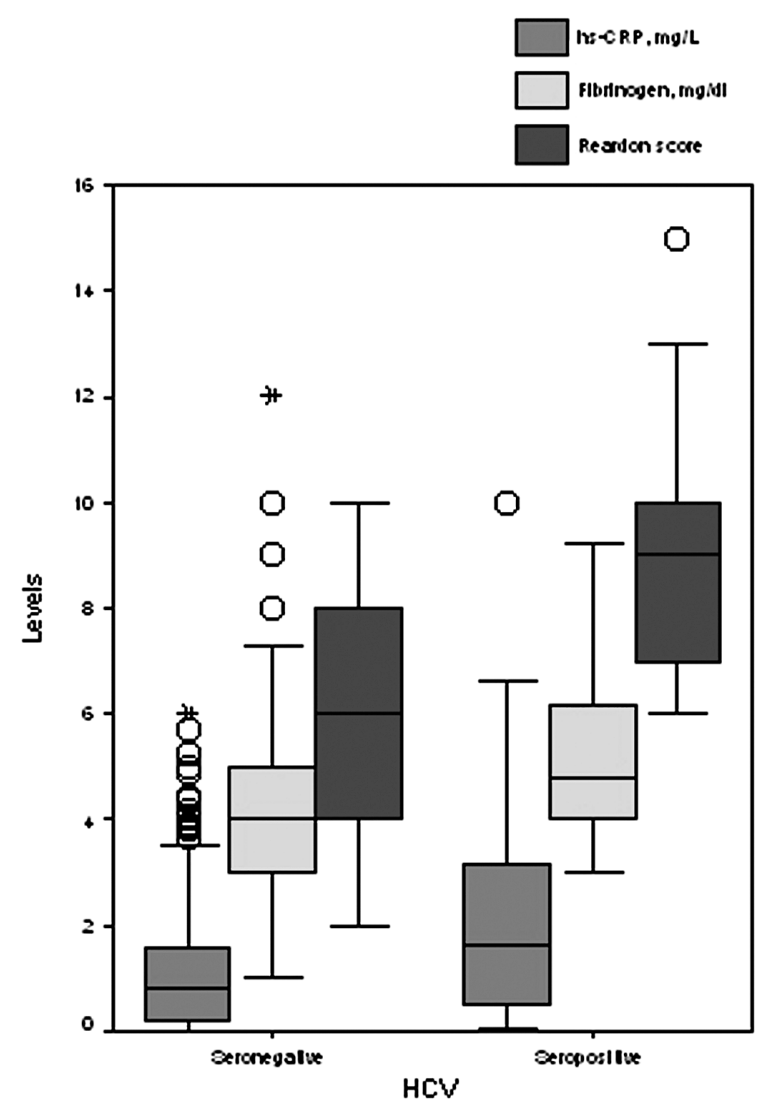

Fig 1. Box plot illustrating the distribution of C-reactive protein (CRP), fibrinogen and Reardon severity score according to hepatitis $\mathrm{C}$ virus (HCV) serology.

gorical variables are presented as percentages and compared with chi-square test or Fisher's exact test. The Pearson correlation was calculated to evaluate the association between 2 continuous variables. For factors that were found to be related to the severity score in the univariate analysis, multivariate regression analyses were performed to determine their impact independently. $\mathrm{P}<0.05$ values were accepted as statistically significant.

\section{Results}

\section{Clinical and Laboratory Data for HCV Seropositives and Controls}

Baseline demographic, laboratory and hemodynamic characteristics of the patients in both groups are illustrated in Table 1. There was no significant difference between the groups in terms of sex, age, and major risk factors attributable to atherosclerotic CAD, such as hypertension, smoking or family history. Diabetes mellitus was much more prevalent in patients with HCV seropositivity compared with the control group, but was not statistically significant (38 $(27.3 \%)$ vs $42(18.7 \%) \mathrm{p}=0.068)$. Hemoglobin A1c values were also similar in both groups $(6.41 \pm 0.63 \%$ in HCV seropositive group vs $6.38 \pm 0.58 \%$ in $\mathrm{HCV}$ seronegative group, $\mathrm{p}=0.358)$. Systolic or diastolic blood pressures were not different when the 2 groups were compared (128.4 \pm 13.5 vs $127.6 \pm 11.8, p=0.873$ and $76.8 \pm 12.9$ vs $75.7 \pm 12.6, p=0.769$, respectively). In addition, the rate of hypertension was similar in the 2 groups (69 (49.6\%) vs $115(51.1 \%) \mathrm{p}=0.829)$. Among the laboratory variables, fasting low-density lipoprotein-cholesterol and triglyceride levels were lower in the $\mathrm{HCV}$ seropositive group compared with the control group (HCV seronegative) $(109.1 \pm 33.5$ vs $118.6 \pm 41.1, \mathrm{p}=0.023$ and $125.4 \pm 55.5$ vs $158.7 \pm 102.4, \mathrm{p}<0.001$, respectively). However, no significant differences were found between groups concerning aspartate transaminase $(27.3 \pm 11.8$ in HCV seropositive vs $25.6 \pm 9.2$ in $\mathrm{HCV}$ seronegative, $\mathrm{p}=$ $0.368)$ or alanine transaminase $(30.1 \pm 12.6$ in $\mathrm{HCV}$ seropsitive vs $27.9 \pm 11.7$ in $\mathrm{HCV}$ seronegative, $\mathrm{p}=0.345)$. In addition, CRP $(2.073 \pm 1.358$ vs $1.190 \pm 1.005, \mathrm{p}<0.001)$ and fibrinogen $(5.323 \pm 1.567$ vs $4.104 \pm 1.648, \mathrm{p}<0.001)$ levels were significantly higher in the HCV seropositive group compared with the control group. Both groups were similar in terms of oral medical treatment including statins, aspirin, angiotensin-converting enzyme inhibitors, angiotensinreceptor blockers, calcium-channel blockers or $\beta$-blockers (Table 2).

\section{Comparisons of the Angiographic Parameters of Patients According to HCV Serology}

When we compared the 2 groups according to angiographic parameters we found that HCV seropositive patients 
Table 4 Independent Predictors of Severity Score by Regression Analysis

\begin{tabular}{lccc}
\hline \hline & Odds ratio & 95\% confidence interval & $p$ value \\
\hline CRP, $\mathrm{mg} / \mathrm{L}$ & 0.277 & $0.096-0.459$ & 0.003 \\
Fibrinogen, $\mathrm{mg} / \mathrm{dl}$ & 0.183 & $0.017-0.350$ & 0.031 \\
HCV seropositivity & 1.565 & $0.963-2.168$ & $<0.001$ \\
\hline
\end{tabular}

Abbreviations see in Table 1.

had more multivessel disease ( $\geq 2$ vessels) than the control group $(126(91.6 \%)$ vs $166(74.1 \%), \mathrm{p}<0.001)$. The percentage of HCV seropositivity increased with the number of vessels affected (3.6\% for 1-vessel disease, $9.6 \%$ for 2 -vessel disease, and $25.1 \%$ for 2 -vessel disease, $\mathrm{p}<0.001$ ). Similarly, the Reardon severity scores were significantly higher in the HCV seropositive group than in the control group $(8.75 \pm 1.69$ vs $6.01 \pm 1.80, \mathrm{p}<0.001)$. In addition, a significant difference was found between the groups in terms of collateral coronary flow. Patients in the HCV seropositive group had more collateral coronary vessels than the control group (32 (23\%) vs $22(9.8 \%), \mathrm{p}=0.001)$ (Table 3$)$. These significant differences between groups might be caused by more inflammation, supported by the higher CRP and fibrinogen levels in the HCV seropositive patients.

\section{Linear Regression Analysis of the Relationship Between $H C V$ Serology and the Severity of $C A D$}

To determine the correlates of the Reardon severity score, correlation analysis was performed and a strong significant positive correlation between the Reardon severity score and CRP $(r=0.24, p=0.002)$, fibrinogen $(r=0.23, p=$ $0.002)$, HCV seropositivity $(r=0.348, p<0.001)$ and the presence of collateral coronary vessels $(r=0.130, p=0.013)$ was found (Fig 1). With increasing levels of CRP and fibrinogen, the Reardon severity score increased, demonstrating more severe CAD.

To detect which clinical and laboratory variables independently affect the Reardon severity score, linear regression analysis including fibrinogen, CRP, anti-HCV seropositivity and the presence of collateral coronary flow was performed. HCV seropositivity (odds ratio (OR): 1.565 (95\% confidence interval (CI) 0.963-2.168, p<0.001)), CRP, and fibrinogen were found to be independent predictors of severity (Table 4). After adjustment for other confounding risk factors, multivariate logistic regression analysis showed that HCV seropositivity still represented an independent predictor for increased atherosclerosis demonstrated by higher Reardon severity score with an OR of 2.018 (95\% CI 1.575-2.579, $\mathrm{p}<0.001)$.

\section{Discussion}

\section{Summary of Findings}

In the present study, we found that HCV seropositivity and the fibrinogen and CRP lvels were independent predictors of increased severity of atherosclerosis. Furthermore, having HCV seropositivity was still a strong independent predictor for the severity of coronary atherosclerosis in multivariateadjusted analysis. Patients with HCV seropositivity had more extensive, severe atherosclerosis than the control group.

\section{Association Between Viral Infectious Agents and Atherosclerosis}

Some infectious agents may cause cellular and molecular changes that contribute to the pathogenesis of atherosclero- sis. ${ }^{10}$ The data obtained identified viral genomes in the atherosclerotic plaques and also the pro-atherogenic effects of viral infection in cells relevant to atherogenesis (ie, smooth muscle cells, monocyte macrophages, $\mathrm{T}$ cells, endothelial cells). Experimental models have also shown promotion and acceleration of atherosclerosis by infectious agents. ${ }^{10}$ One of the infections studied in atherogenesis is hepatitis B virus (HBV) infection. Kiechl et al reported a relationship between hepatitis and carotid atherosclerosis and found no significant difference between chronic hepatitis and the carotid atheromatous plaque, although whether each subject had HBV or HCV was not specified? Similarly, in a recent study Yang et al found no association between HBsAg seropositivity and increased carotid atherosclerosis in Taiwanese ${ }^{16}$ However, in a cross-sectional cohort study including 4,686 subjects of whom 1,294 (28\%) had carotid atherosclerosis and $40(0.9 \%)$ had HBsAg seropositivity, Ishizaka et $\mathrm{al}^{17}$ suggested the possible role of chronic HBV infection in the pathogenesis of carotid atherosclerosis. Some possible mechanisms to explain the relationship between HBV infection and atherosclerosis have been suggested. First, HBV may colonize the vascular tissues ${ }^{18}$ leading to vascular damage. Second, HBV infection occasionally is associated with vasculitis 19 Third, chronic HBV infection may be associated with increased levels of oxidative stress, ${ }^{20}$ which may accelerate atherogenesis. Finally, chronic HBV infection may stimulate inflammatory and immune-mediated responses.

$\mathrm{HCV}$ is a worldwide public health problem and frequently leads to chronic hepatitis, which may progress to cirrhosis and even to hepatocellular carcinoma ${ }^{21-23}$ The incidence of HCV seropositivity is $0.3 \%$ in total blood of donors in Turkey. The prevalence of anti-HCV seropositivity in volunteers is less than $0.2 \%$ in North Europe and United States, while it is $1-1.5 \%$ in South Europe and Japan? 24,25 The mechanisms responsible for the pathogenesis of chronic $\mathrm{HCV}$ infection are not well known. Similarly, there are very few data about the possible relationship between HCV infection and its association with atherosclerosis. The first reports of the effect of $\mathrm{HCV}$ infection on atherogenesis were regarding carotid atherosclerosis. Ishizaka et al ${ }^{26}$ found that carotid artery plaque was far more prevalent in the core-protein of HCV seropositive subjects (64\%) than in core-protein negative subjects $(24 \%)$ in a study of 1,992 subjects. They concluded that HCV core protein positivity was positively and independently associated with carotid plaque with an OR of 5.61 (95\% CI 2.06-15.26). Similarly, in another study designed by Ishizaka et al, HCV seropositivity was found to be associated with an increased risk of carotid artery plaque with an OR of 1.92 (95\% CI 1.56$2.38, \mathrm{p}=0.002$ ) and carotid intima-media thickening with an OR of $2.85(95 \%$ CI $2.28-3.57, \mathrm{p}<0.001))^{11}$ These findings suggest a possible role for chronic hepatitis $\mathrm{C}$ in the pathogenesis of carotid arterial remodeling.

The first evidence for an association between HCV seropositivity and CAD was reported by Vassalle et al27 They 
showed that in addition to other conventional atherogenic risk factors (ie, age, sex, smoking habit, hypertension, diabetes, and dyslipidemia), HCV seropositivity was associated with the presence of CAD with an OR of $3.2(95 \% \mathrm{CI}$ 1.1-9.2). However, Arcari et $\mathrm{al}^{28}$ investigated the association between HCV seropositivity and acute myocardial infarction using a well-established cohort of young men in the US military and found no evidence to support this association.

In addition to atherosclerosis, HCV may be involved in cardiovascular diseases such as myocarditis and cardiomyopathies. Matsumori et al ${ }^{29}$ evaluated patients enrolled in the Myocarditis Treatment Trial (MTT) and showed that antiHCV antibodies were identifiable in sera stored for 13-17 years and were more prevalent in patients with myocarditis and HF than in the general population and they concluded that in regions where prevalence of $\mathrm{HCV}$ was high, $\mathrm{HCV}$ infection might be an important cause of myocarditis and HF.

No data are available in the current literature with regard to the association between $\mathrm{HCV}$ infection and severity of atherosclerosis. In the present study we investigated the association between HCV seropositivity and the severity of coronary atherosclerosis using a modified Reardon score system and found that HCV seropositivity was an independent risk factor for increased atherosclerosis demonstrated by higher Reardon severity scores with an OR of 1.565 (95\% CI 0.963-2.168). Furthermore, after adjustment for other risk factors, including CRP and fibrinogen, we found that $\mathrm{HCV}$ seropositivity still represented an independent predictor of severity or increased coronary atherosclerosis with an OR of 2.018 (95\% CI 1.457-2.579). Similar to HBV infection, HCV infection may also stimulate inflammatory and immune-mediated responses, leading to increased inflammation, or it may increase levels of oxidative stress on atherosclerotic plaque. In other words, increased atherosclerosis in $\mathrm{HCV}$ seropositive subjects might be related to increased oxidative stress on atherosclerotic plaque and more inflammation, as demonstrated by high levels of fibrinogen in the seropositive subjects. In the present study, as a result of more inflammation because of HCV infection, patients in the HCV seropositive group had more extensive and severe atherosclerosis, demonstrated by higher Reardon scores, more multivessel disease and more collateral coronary vessels than the control group.

Previous studies have reported that the severity of coronary disease by the Reardon scoring system has a significant relation to traditional coronary risk factors such as high lowdensity lipoprotein level and diabetes mellitus. However, in the present study, low-density lipoprotein and triglyceride levels were lower in the HCV seropositive group, which may be related to reduced synthesis of low-density lipoprotein because of the increased inflammation at tissue level in this group or to interaction between the HCV infection and $\beta$ lipoprotein metabolism. The $\beta$-lipoproteins competitively inhibit $\mathrm{HCV}$ infection, because both $\mathrm{HCV}$ and $\beta$-lipoprotein use the same low-density lipoprotein receptor 30 Similarly with the cholesterol level.

The prevalence of diabetes mellitus was higher in the HCV seropositive group (statistically insignificant) than in the control group. Even though it was statistically insignificant, the higher rate of diabetes mellitus in HCV seropositive patients may have contributed to the increased atherosclerosis and Reardon severity score compared with the control group.

In the present study, the higher fibrinogen and CRP levels in the HCV seropositive group suggest greater severity of atherosclerosis. Fibrinogen, an acute-phase protein, is strongly associated with (preclinical) atherosclerosis and also with a number of cardiovascular risk factors, notably smoking? ${ }^{3-33}$ Elevated fibrinogen, reflecting the level of inflammatory activity, is associated with progression of carotid atherosclerosis, as was demonstrated previously for other inflammatory parameters such as CRP ${ }^{34}$ Hashimoto et $\mathrm{al}^{35}$ demonstrated that the high-sensitivity (hs) CRP concentration is an independent predictor of the development of early carotid atherosclerosis. They showed that hs-CRP was a marker of inflammation related to the rate of plaque development rather than of the extent or severity of the plaque burden. Similarly, Tracy et al ${ }^{36}$ found no association between CRP and the severity of carotid atherosclerosis in a cross-sectional study of hs-CRP. Nascimento et al ${ }^{37}$ suggested that hs-CRP was a less useful marker of inflammation and could not indicate inflammation in HCV seropositive patients. In another study, Floris-Moore et al ${ }^{38}$ showed that HCV infection was associated with lower levels of lipids and hs-CRP in HIV-infected men. However, in the present study, the hs-CRP levels were higher in the HCV seropositive patients. Furthermore we found a weak, but statistically significant, positive correlation between CRP and the severity of coronary atherosclerosis $(r=0.24, p=0.002)$. In lights of these findings we suggest that increased coronary atherosclerosis, as demonstrated by a high Reardon score, in HCV seropositive patients is related to increased hs-CRP and more inflammation secondary to $\mathrm{HCV}$ infection.

\section{Conclusions}

We have demonstrated an association between HCV infection and the severity of coronary atheroslerosis. The possible mechanism may be more inflammation secondary to infection, which is a similar effect of $\mathrm{HBV}$ infection on atherosclerosis.

\section{Study limitations}

We used a visual scoring system. Even if there was no significant difference between the scores of 2 reviewers, evaluation of coronary angiograms by automatic computer programs may obtain more accurate (optimal) scores. Our study only included HCV seropositive patients without clinical liver disease or cirrhosis. Therefore, the cumulative effect of HCV infection on the severity of coronary atherosclerosis was not determined. We evaluated atherosclerosis only in the main coronary arteries and stenosis of a minor vessel or a main coronary artery branch was excluded in order to detect the effect of $\mathrm{HCV}$ infection on atherosclerosis of the main coronary arteries that mainly affect the choice for revascularization. In addition, our study population was too small to reach a conclusion, but this is first study showing a relationship between HCV infection and the severity of coronary atherosclerosis. Large-scale studies demonstrating more exactly the effect of $\mathrm{HCV}$ infection on the severity of atherosclerosis are needed.

\section{References}

1. Saikku P. Chlamydia pneumoniae in atherosclerosis. J Intern Med 2000; 247: 391-396.

2. Shimada K, Daida H, Mokuno H, Watanabe Y, Sawano M, Iwama Y, et al. Association of seropositivity for antibody to Chlamydia-specific lipopolysaccharide and coronary artery disease in Japanese men. Jpn Circ J 2001; 65: 182-187.

3. Adam E, Melnick JL, Probtsfield JL, Petrie BL, Burek J, Bailey KR, et al. High levels of cytomegalovirus antibody in patients requiring 
vascular surgery for atherosclerosis. Lancet 1987; 2: 291-293.

4. Mendall MA, Goggin PM, Molineaux N, Levy J, Toosy T, Strachan $\mathrm{D}$, et al. Relation of Helicobacter pylori infection and coronary heart disease. Br Heart J 1994; 71: 437-439.

5. Yamashiroya HM, Ghosh L, Yang R, Robertson AL Jr. Herpesviridae in the coronary arteries and aorta of young trauma victims. Am J Pathol 1988; 130: 71-79.

6. Chiu B, Viira E, Tucker W, Fong IW. Chlamydia pneumoniae, cytomegalovirus, and herpes simplex virus in atherosclerosis of the carotid artery. Circulation 1997; 96: 2144-2148.

7. Zhu J, Quyyumi AA, Norman JE, Costello R, Csako G, Epstein SE. The possible role of hepatitis A virus in the pathogenesis of atherosclerosis. J Infect Dis 2000; 182: 1583 - 1587 [Erratum: J Infect Dis 2001; 183: 521].

8. Kiechl S, Egger G, Mayr M, Wiedermann CJ, Bonora E, Oberhollenzer F, et al. Chronic infections and the risk of carotid atherosclerosis: Prospective results from a large population study. Circulation 2001; 103: 1064-1070.

9. Ludewig B, Freigang S, Jaggi M, Kurrer MO, Pei YC, Vlk L, et al. Linking immune-mediated arterial inflammation and cholesterolinduced atherosclerosis in a transgenic mouse model. Proc Natl Acad Sci USA 2000; 97: 12752-12757.

10. Shah PK. Link between infection and atherosclerosis: Who are the culprits: Viruses, bacteria, both, or neither? Circulation 2001; 103: $5-6$.

11. Ishizaka $\mathrm{N}$, Ishizaka $\mathrm{Y}$, Takahashi $\mathrm{E}$, Tooda $\mathrm{E}$, Hashimoto $\mathrm{H}$, Nagai $\mathrm{R}$, et al. Association between hepatitis $\mathrm{C}$ virus seropositivity, carotidartery plaque, and intima-media thickening. Lancet 2002; 359: 133 135.

12. Jenkins PJ, Harper RW, Nestel PJ. Severity of coronary atherosclerosis related to lipoprotein concentration. BMJ 1978; 2: 388-391.

13. Reardon MF, Nestel PJ, Craig IH, Harper RW. Lipoproteins predictors of the severity of coronary artery disease in men and women. Circulation 1985; 71: 881-888.

14. Colin C, Lanoir D, Touzet S, Meyaud-Kraemer L, Bailly F, Trepo C Sensitivity and specificity of third-generation hepatitis $\mathrm{C}$ virus antibody detection assays: An analysis of the literature. J Viral Hepat 2001; 8: 87-95.

15. Pawlotsky JM, Lonjon I, Hezode C, Raynard B, Darthuy F, Remire J, et al. What strategy should be used for diagnosis of hepatitis $\mathrm{C}$ virus infection in clinical laboratories? Hepatology 1998; 27: 1700-1702.

16. Yang KC, Chen MF, Su TC, Jeng JS, Hwang BS, Lin LY, et al. Hepatitis B virus seropositivity is not associated with increased risk of carotid atherosclerosis in Taiwanese. Atherosclerosis 2007; 195: $392-397$.

17. Ishizaka N, Ishizaka Y, Takahashi E, Toda Ei E, Hashimoto H, Ohno $\mathrm{M}$, et al. Increased prevalence of carotid atherosclerosis in hepatitis B virus carriers. Circulation 2002; 105: 1028-1030.

18. Mason A, Wick M, White H, Perrillo R. Hepatitis B virus replication in diverse cell types during chronic hepatitis B virus infection. Hepatology 1993; 18: 781-789.

19. Guillevin L, Lhote F, Gherardi R. The spectrum and treatment of virus-associated vasculitides. Curr Opin Rheumatol 1997; 9: 31-36.

20. Sumida Y, Nakashima T, Yoh T, Furutani M, Hirohama A, Kakisaka $\mathrm{Y}$, et al. Serum thioredoxin elucidates the significance of serum ferritin as a marker of oxidative stress in chronic liver diseases. Liver 2001; 21: 295-299.

21. Ebeling F. Epidemiology of the hepatitis C virus. Vox Sang 1998;
74(Suppl): 143-146.

22. Memon MI, Memon MA. Hepatitis C: An epidemiological review. $J$ Viral Hepat 2002; 9: 84-100.

23. Niederau C, Lange S, Heintges T, Erhadt A, Buschlamp M, Hurter D, et al. Progression of chronic hepatitis C: Results of a large prospective cohort study. Hepatology 1998; 28: 1687-1695.

24. Di Biceglie AM. Hepatitis C. Lancet 1998; 251: 351-355.

25. Alter MJ. Epidemiology of hepatitis C in west. Semin Liver Dis 1995; 15: 5-14.

26. Ishizaka Y, Ishizaka N, Takahashi E, Unuma T, Tooda E, Hashimoto $\mathrm{H}$, et al. Association between hepatitis $\mathrm{C}$ virus core protein and carotid atherosclerosis. Circ J 2003; 67: 26-30.

27. Vassalle C, Masini, Bianchi F, Zucchelli GC. Evidence for association between hepatitis $\mathrm{C}$ virus seropositivity and coronary artery disease. Heart 2004; 90: $565-566$.

28. Arcari CM, Nelson KE, Netski DM, Nieto FJ, Gaydos CA. No association between hepatitis $\mathrm{C}$ virus seropositivity and acute myocardial infarction. Clin Infect Dis 2006; 43: 53-56.

29. Matsumori A, Shimada T, Chapman NM, Tracy SM, Mason JW. Myocarditis and heart failure associated with hepatitis $\mathrm{C}$ virus infection. J Card Fail 2006; 12: 293-298.

30. Petit JM, Bour JB, Gallant-Jos C, Minello A, Verges B, Guiguet M, et al. Risk factors for diabetes mellitus and early insulin resistance in chronic hepatitis C. J Hepatol 2001; 35: 279-283.

31. Krobot K, Hense HW, Cremer P, Eberle E, Keil U. Determinants of plasma fibrinogen: Relation to body weight, waist-to-hip ratio, smoking, alcohol, age, and sex: Results form the Second MONICA Augsburg Survey, 1989-1990. Arterioscler Thromb 1992; 12: 780 788.

32. Folsom AR, Conlan MG, Davis CE, Wu KK. Relations between hemostasis variables and cardiovascular risk indicators in middle aged adults. Ann Epidemiol 1992; 2: 481-494.

33. Lee AJ, Lowe GDO, Woodward M, Tunstall-Pedoe H. Fibrinogen in relation to personal history of prevalent hypertension, diabetes, stroke, intermittent claudication, coronary heart disease, and family history: The Scottish Heart Health Study. Br Heart J 1993; 69: 338 342.

34. Sabeti S, Exner M, Mlekusch W, Amighi J, Quehenberger P, Rumpold H, et al. Prognostic impact of fibrinogen in carotid atherosclerosis: Nonspecific indicator of inflammation or independent predictor of disease progression? Stroke 20051; 36: 1400-1404.

35. Hashimoto H, Kitagawa K, Hougaku H, Shimizu Y, Sakaguchi M, Nagai Y, et al. C-reactive protein is an independent predictor of the rate of increase in early carotid atherosclerosis. Circulation 2001; 104: $63-67$

36. Tracy RP, Psaty BM, Macy E, Bovill EG, Cushman M, Cornell ES, et al. Lifetime smoking exposure affects the association of C-reactive protein with cardiovascular disease risk factors and subclinical disease in healthy elderly subjects. Arterioscler Thromb Vasc Biol 1997; 17: 2167-2176.

37. Nascimento MM, Bruchfeld A, Suliman ME, Hayashi SY, PecoitsFilho R, Manfro RC, et al. Effect of hepatitis C serology on C-reactive protein in a cohort of Brazilian hemodialysis patients. Braz $J$ Med Biol Res 2005; 38: 783-788.

38. Floris-Moore M, Howard AA, Lo Y, Schoenbaum EE, Arnsten JH, Klein RS. Hepatitis C infection is associated with lower lipids and high-sensitivity C-reactive protein in HIV-infected men. AIDS Patient Care STDS 2007; 21: 479-491. 